\title{
AC 2012-3087: DEVELOPMENT OF A POWER ELECTRONICS LAB COURSE WITH RENEWABLE ENERGY APPLICATIONS
}

Mr. David S. Ochs, Kansas State University

David S. Ochs received his bachelor's of science in electrical engineering from Kansas State University in 2010. He is currently pursuing a master's of science at Kansas State University. His research interests include power electronics and maximum power capture in wind energy systems.

\section{Dr. Ruth Douglas Miller, Kansas State University}

Ruth Douglas Miller earned a B.S.E.E. from Lafayette College and M.S. and Ph.D. degrees, both in electrical engineering, from the University of Rochester. She has taught at Kanssa State University for 21 years and is presently Associate Professor. She directs the Kansas Wind Applications Center and teaches wind and solar energy system design, as well as undergraduate classes in electronics, electromagnetics, and engineering ethics. 


\section{DEVELOPMENT OF A POWER ELECTRONICS LAB COURSE WITH RENEWABLE ENERGY APPLICATIONS}

\section{Introduction}

It is widely accepted, and much research has shown, that laboratory experience is an essential part of a good education in power electronics ${ }^{1-6}$. Engineering students at Kansas State University have many opportunities for hands-on learning in lab classes, and this work provides them with one more. The field of power electronics is growing rapidly, thanks in large part to greater penetration of renewable energy systems in power grids ${ }^{7}$. Because renewable energy systems are becoming a greater part of our energy portfolio, engineers are needed who are familiar with the unique challenges and opportunities presented by them. Many renewable energy systems rely heavily on power electronics, so experience with them goes a long way towards making an engineer competent to work with such systems. The power electronics laboratory class presented provides students with opportunities for designing, testing, evaluating, and troubleshooting power electronics circuits. Students explore power electronics and see how they apply to renewable energy by using solar panels, wind turbine models, and an actual wind turbine as part of the exercises.

The organization, pedagogical approach, and goals of a new course on power electronics with renewable energy applications are presented. A summary of the equipment needed for the course and two sample labs and a final project are presented as well. A first iteration of this new course has been completed by four undergraduate students and one graduate student, and their feedback is presented.

\section{Organization of the course}

Many new laboratory classes in power electronics have been developed in recent years, making use of various pedagogical techniques ${ }^{1-6}$. For this lab, the authors chose to combine traditional, instruction-based labs with project-based elements that have become popular lately ${ }^{3,6}$. That combination provides students with adequate guidance for learning how to use equipment they're not familiar with and reinforcing basic concepts. Furthermore, students are given many opportunities to find their own solutions to engineering problems. The course is designed to be worth two or three credit hours, with three hours of lab time and one hour of lecture per week. The labs are designed to be done by senior-level undergraduate or graduate students working in teams of two or three. The labs are organized around two major types of renewable electricity generators: photovoltaics and wind turbines. Many, if not all, of the power electronics concepts covered have applications in both wind energy and solar energy systems. Those topics and their sub-topics are in the course outline in Figure 1.

$\underline{\text { Solar Labs }}$

1. Classifying solar panels

i. I-V curves, temperature effects, bypass diodes 
2. Power semiconductor devices and gate driving

i. IGBT and MOSFET characteristics, totem pole and optocoupler gate drivers

3. DC/DC converters (choppers)

i. Buck choppers, Boost Choppers, Boost choppers with PV panels

4. Single-phase voltage source inverters and filters

i. H-bridge VSI's, THD, RLC filters

5. Single-phase current source inverters

i. H-bridge CSI topology, CSI's with PV panels, circuit construction on breadboards

Wind Labs

6. Permanent-magnet synchronous generators \& induction generators

i. Comparison between types of generators, power curve of Air Breeze wind turbine

7. Rectifiers and freewheeling diodes

i. H-bridge diode rectifiers, three-phase rectifiers, freewheeling diodes with inductive loads

8. Pulse-width modulation (PWM) for voltage source inverters

i. Uniform PWM, Sinusoidal PWM, THD, circuit construction on breadboards

9. Three-phase voltage source inverters and snubbers

i. Six-step and PWM operation of three-phase VSI's, comparison of snubber circuits

Final Project

10. Solar MPPT based on a boost chopper

or

11. Full converter for a permanent-magnet wind turbine generator

Figure 1. Lab course outline

Every lab except numbers 2 and 11 were completed by three undergraduate students and one graduate student during the fall 2011 semester. Those labs, with the exception of Lab 5, were also completed by another undergraduate student during the summer of 2011. Feedback was taken directly from the students as they worked through the lab experiments and the labs were adjusted based on that. Those changes are reflected in the sample labs presented below.

Anonymous feedback was also collected as part of end-of-semester evaluations and is presented below. Each lab is divided into Pre-Lab and Lab Exercises sections. The Pre-Lab parts consist of multiple choice or short answer questions designed to get students thinking about what they'll be doing in the lab. Sometimes the Pre-Lab is used to introduce topics to be used during the lab as well. The Lab Exercises sections contain instructions on what to do in the lab. 
One set of new equipment for this lab was purchased through a grant from the US Department of Energy (DE-EE0003544). Much of the new equipment was purchased from Lab-Volt Systems Inc. That equipment includes a multi-use chopper/inverter, a data acquisition and control module, loads, filters, power supplies, a dynamometer/motor, and software for computer-based instrumentation and control. A 2400 Sourcemeter made by Keithley Instruments Inc. was also purchased specifically for this lab. The Lab-Volt equipment (without the dynamometer/motor) and the Sourcemeter are shown in Figures 2 and 3.

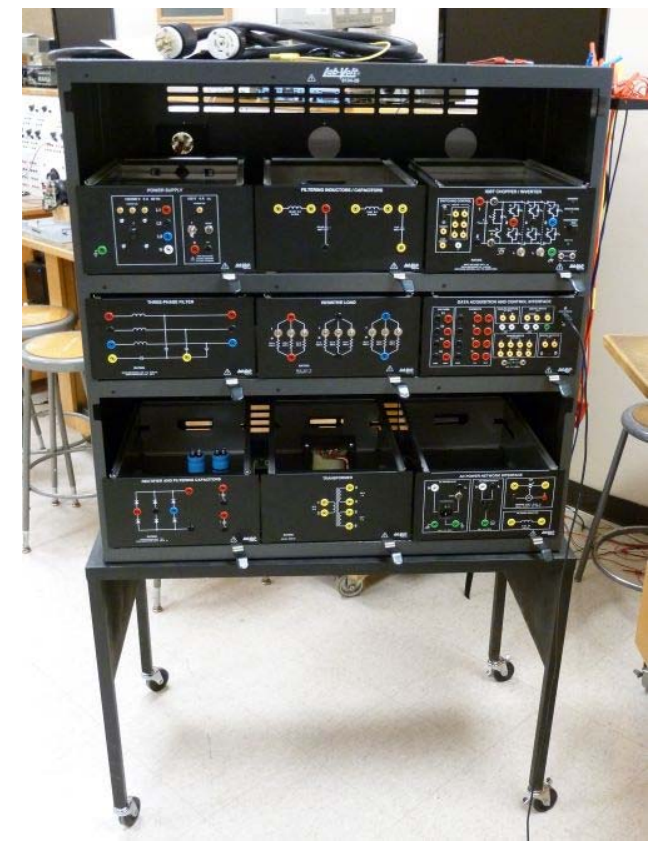

Figure 2. Lab-Volt equipment

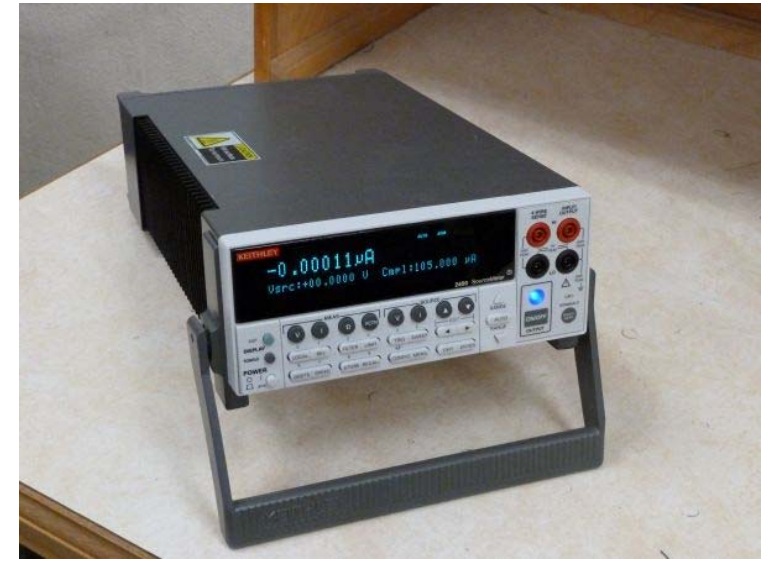

Figure 3. 2400 Sourcemeter

The Lab-Volt chopper/inverter module can accept gating signals generated by either the LabVolt data acquisition and control (DAC) module, or from a circuit constructed by the students. This provides a great deal of flexibility. For example, students can use the DAC to run a $180^{\circ}$ modulation mode inverter, then build their own PWM gating circuit and connect it right to the chopper/inverter module.

This course also utilizes equipment that the Department of Electrical and Computer Engineering already owned, such as computers, small PV panels, worklights, small electric machines, and an Air Breeze wind turbine made by Southwest Windpower. Students also have the department's parts shop available to them to give them access to electronic components.

\section{Course objectives}

There are two primary objectives of this course. The first is to allow students to work with and design many different types of power electronic circuits in a lab setting. This will supplement the power electronics lecture course, where students learn the theory behind such circuits and simulate them. As students who have taken this course have discovered, there is often a significant difference between simulating a circuit and actually building and using it. The second 
primary objective is to allow students to see the many applications of power electronics to renewable energy systems firsthand. Secondary objectives include reinforcing basic electronics lab skills such as circuit prototyping, using lab equipment such as oscilloscopes, DMM's, and power supplies, and building students' teamwork and problem-solving skills.

\section{Pedagogical Approach}

The power electronics lab presented in this paper combines many different aspects of engineering into a single course. In keeping with the primary objective of the course, the lab has been designed to expose students to many different types of power electronics circuits. Some labs have made use of the Lab-Volt equipment's capabilities to rapidly prototype and operate circuits, eliminating the need for detailed design. That allows students to see how such circuits work without getting bogged down in details. Other labs, however, require the students to build nearly every part of the circuit from components available in our department's parts shop. Building circuits "from scratch" forces students to understand how every part of the circuit works, while rapidly prototyping allows students to see the "end product" without spending hours on circuit design. The authors feel that both approaches are appropriate for a modern power electronics lab.

\section{Sample Lab Experiments}

\section{A. DC/DC Converters (Choppers)}

In this lab the students make extensive use of the rapid prototyping capabilities of the Lab-Volt equipment. Students begin by configuring the chopper/inverter module as a buck converter. They run the converter at several different frequencies and duty cycles and note the effects of both (if any). This part of the lab allows students to use a fairly simple circuit to get acclimated to the Lab-Volt equipment and user interface. Next the students move on to work with a boost converter such as the one shown in Figure 4 and explained in Rashid's text ${ }^{8}$.

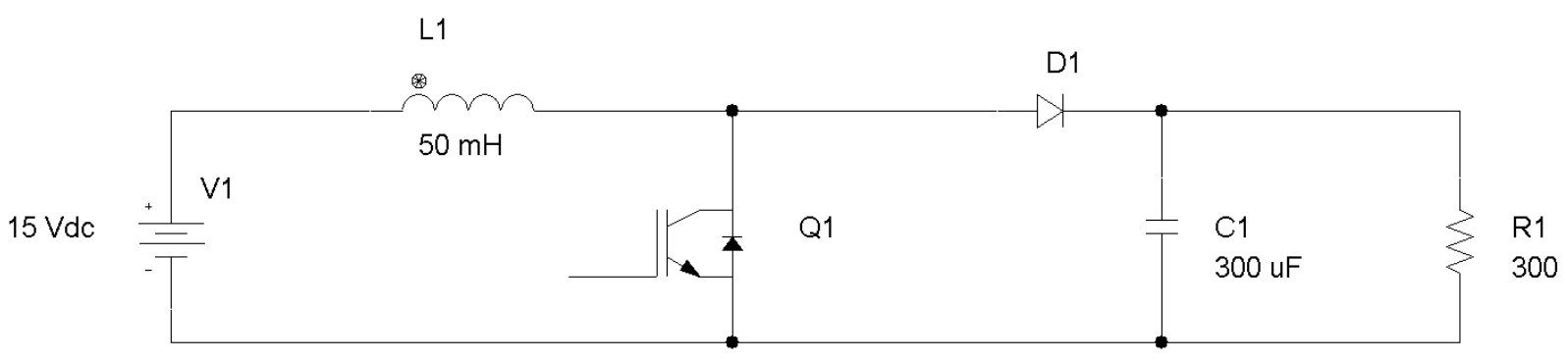

Figure 4. Boost DC/DC converter

They investigate the effects of frequency and duty cycle on the output voltage and the inductor current using the Lab-Volt tools. For example, Figure 5 shows the output current as captured by the DAC at two different duty cycles. 

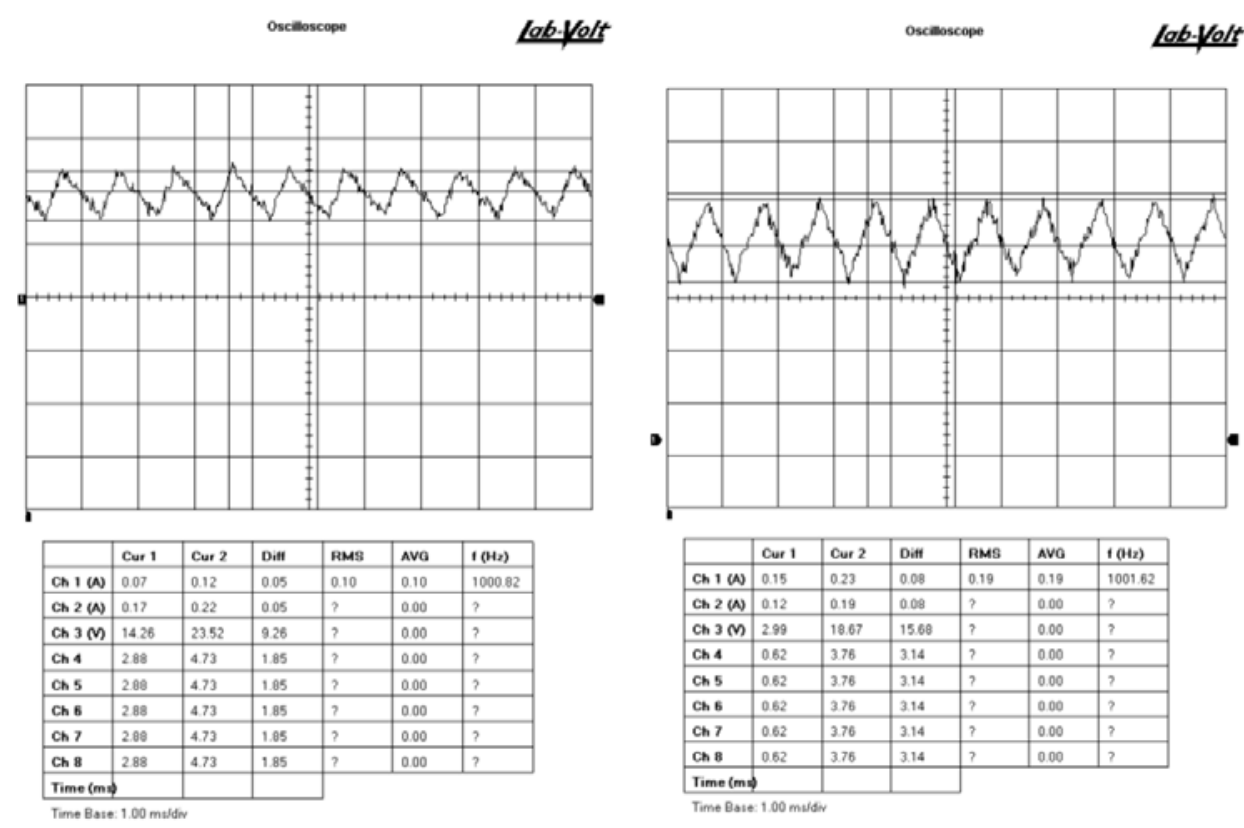

Figure 5. Boost converter inductor currents for different duty cycles

Students then use the Lab-Volt software's automated data capture feature to collect voltage, current, power, and efficiency data for different duty cycles. Then they plot some of the results with the same software.

Students next exchange the DC power supply for a 10W solar panel as the input to the boost converter. A previous lab was partially dedicated to obtaining I-V curves for the solar panels. Students use those curves to predict the maximum power point of the panel, then run the boost chopper and see if they can achieve it by varying the duty cycle. Figure 6 shows a curve like one they might take when running this test.

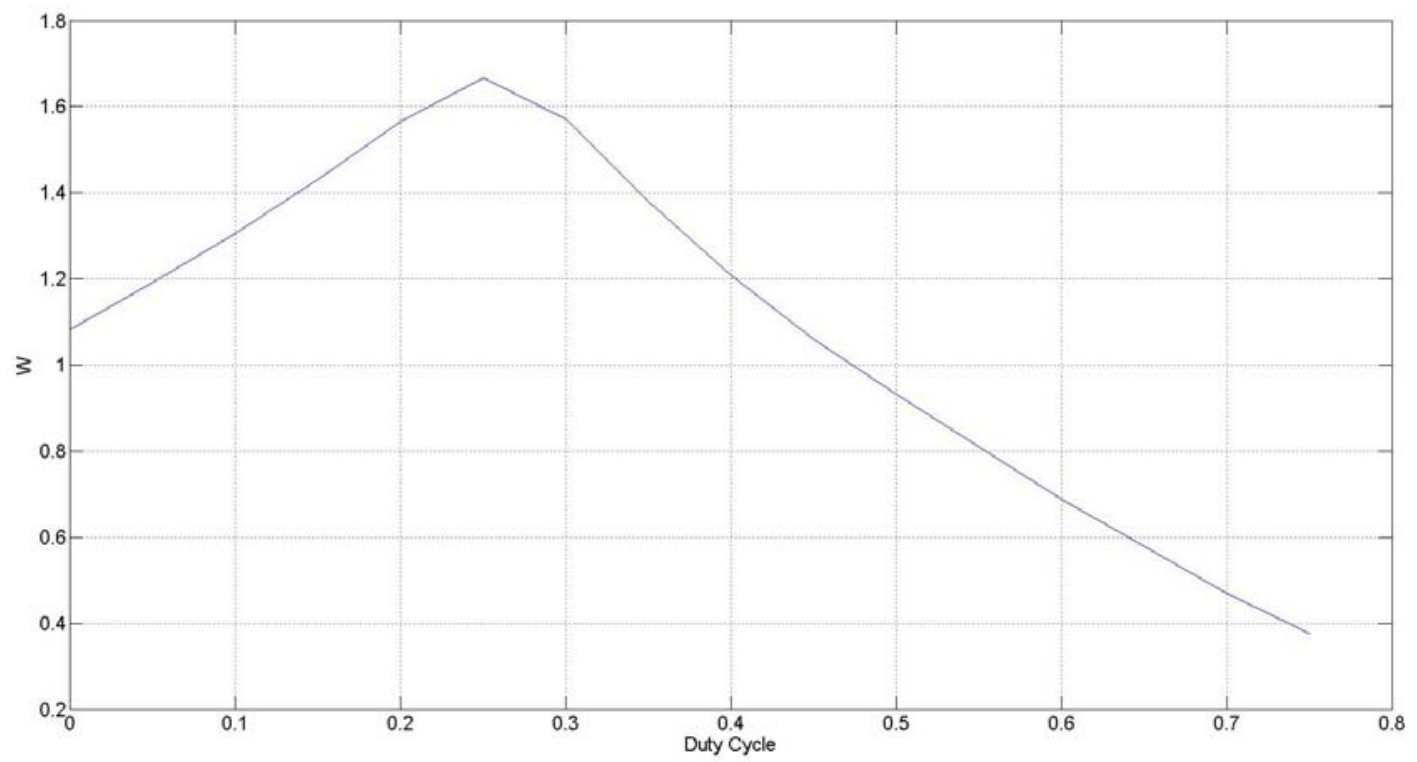

Figure 6. PV panel power vs. boost converter duty cycle 
Students' data shows them that using a boost chopper with a PV panel is much different from using it with a dc power supply. For example, they're instructed to plot the input and output voltages of the chopper over a range of duty cycles. That plot is shown in Figure 7.

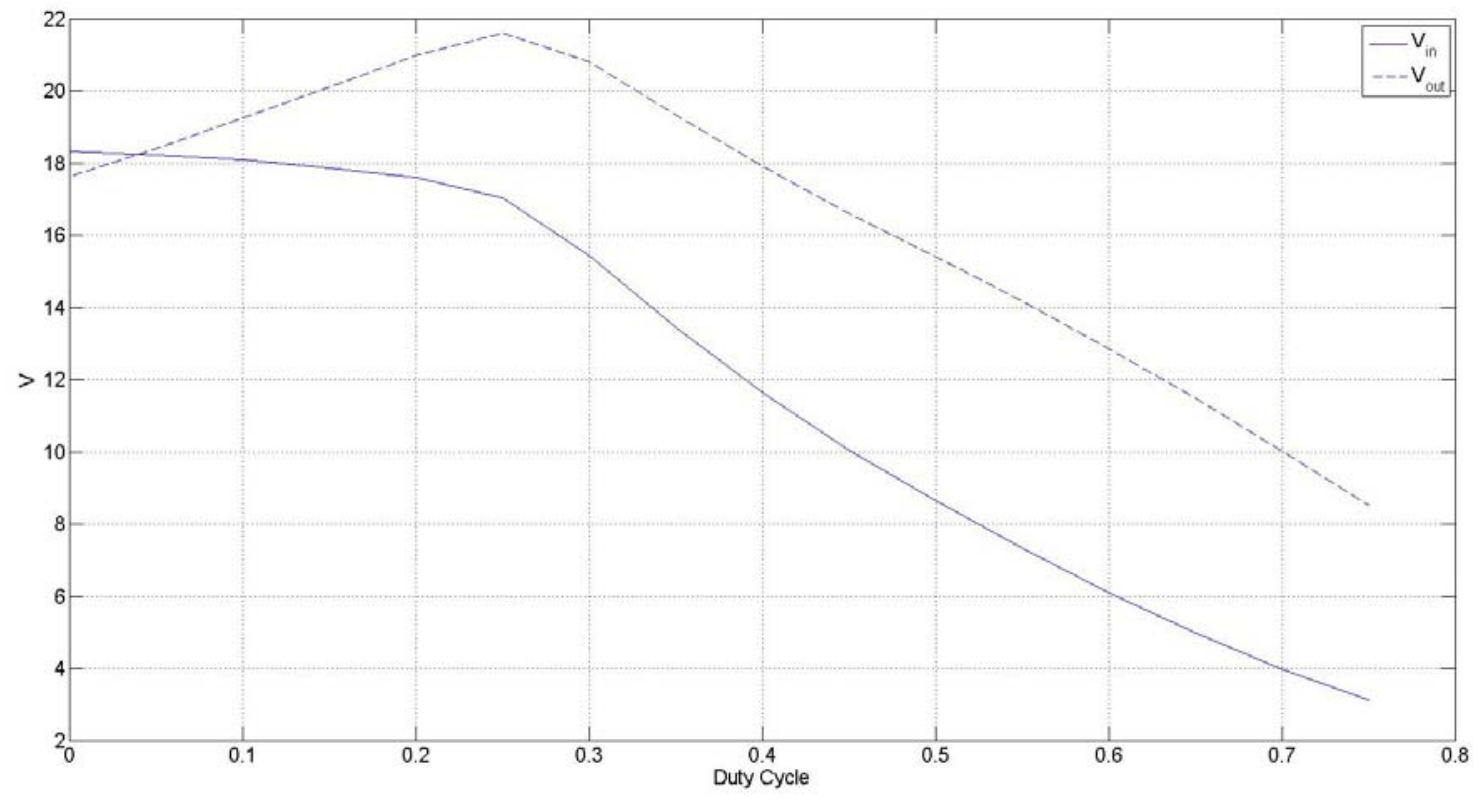

Figure 7. Input and output voltages of a boost chopper vs. duty cycle, PV input

The relationship between input and output voltage is the same as when a DC power supply acts as the input, but now both $\mathrm{V}_{\text {in }}$ and $\mathrm{V}_{\text {out }}$ change with duty cycle, instead of just $\mathrm{V}_{\text {out }}$. That's one example of the additional learning opportunities gained by having the lab experiments directly incorporate renewable technologies.

Finally, students are instructed to take one last set of data with a different amount of irradiation incident to the solar panel. They're then asked questions that lead them to discover that the ratio between the voltage at the maximum power point $\left(\mathrm{V}_{\text {mpp }}\right)$ and the open circuit voltage $\left(\mathrm{V}_{\text {oc }}\right)$ of the panel is approximately constant between irradiation levels. They can then use that fact, and the ratio they find, in their design if they choose to do the maximum power point tracker final project at the end of the semester.

\section{B. Pulse-Width Modulation (PWM) for Voltage Source Inverters}

The pulse-width modulation experiment is one in which the students must construct almost every part of their circuit themselves. They rely very little on the Lab-Volt equipment's rapid prototyping capabilities. This lab doesn't have any direct usage of renewable technology in it, but students know from previous labs that inverters are integral parts of both wind and solar energy systems. The premise of this lab is to build and analyze two different types of PWM inverters. Students are given a basic topology for each type of PWM gating signal generation circuit, and then they must make several design decisions themselves and construct the circuits. 
They then use the gating signals they've obtained to run the Lab-Volt chopper/inverter module as a voltage source inverter (VSI) and analyze the results. The two types of PWM used are uniform pulse-width modulation and sinusoidal pulse-width modulation, the theory behind each of which is explained by Rashid ${ }^{8}$.

The Pre-Lab section consists of questions on the theory of how PWM gating signals are generated. For example, in one question students are shown a sine wave overlain on a triangle wave carrier signal and asked to draw the result if the two were inputs to a comparator.

The first type of PWM the students use is uniform (UPWM). The second half of the lab has the students implementing sinusoidal PWM (SPWM). Figure 8 shows the schematic of the SPWM circuit the authors built as a demonstration.
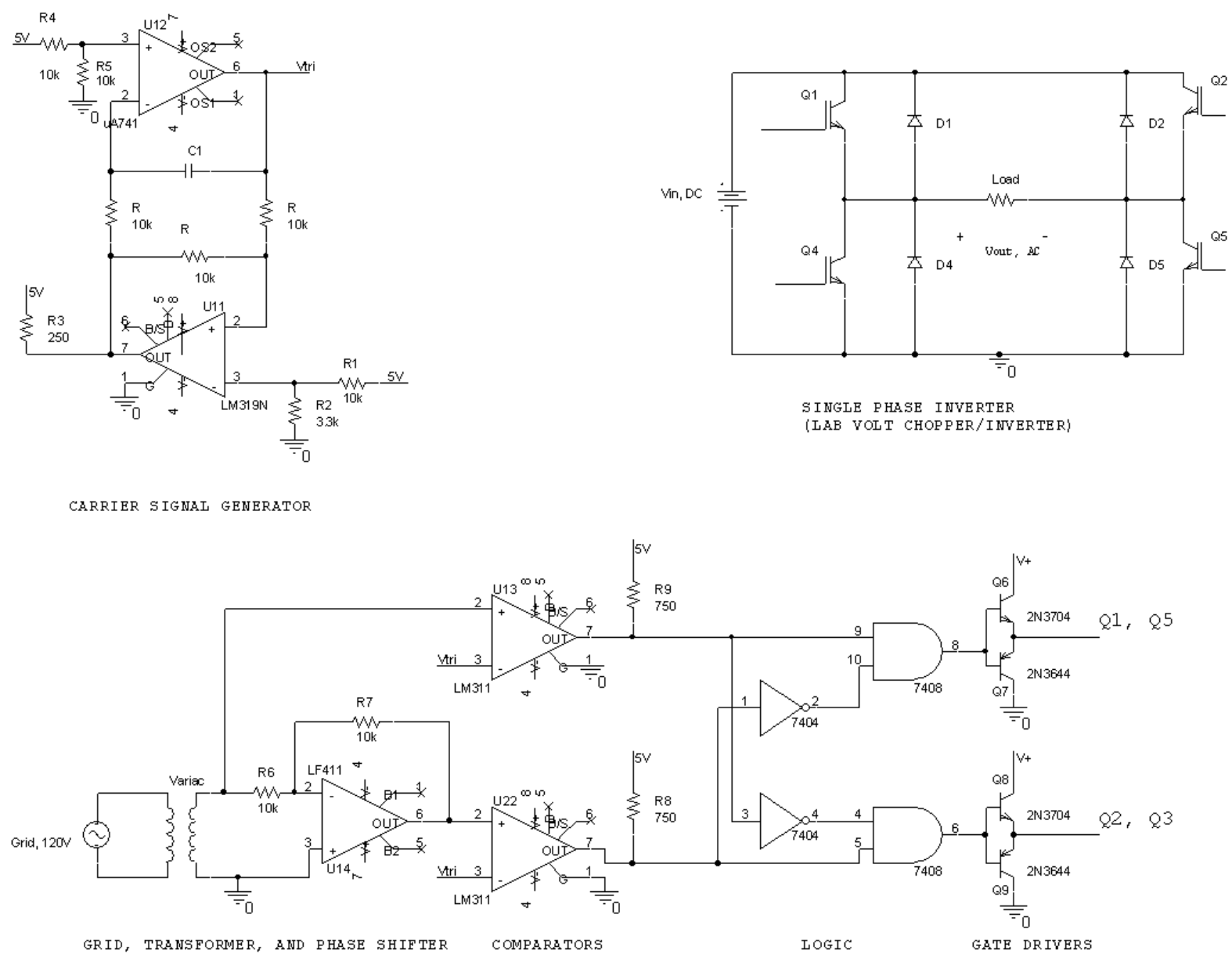

Figure 8. SPWM inverter schematic

Students are given the schematic for the "carrier signal generator" in Figure 8 and the formula for the frequency of its triangle wave output (carrier signal frequency). They then must choose that frequency and pick a value of C1 to achieve it. Students are told that, given a 120V signal from the grid, they must scale it down and shift it $180^{\circ}$ for use in this lab. The "grid, transformer, and phase shifter" part of Figure 8 is one way of achieving that. The students are then instructed to construct the "comparators" and "gate drivers" portions of Figure 8. They must design the 
"logic" portion on their own to ensure that the gating signals are never high at the same time. There are many different logic circuits that will work, one of which is shown in Figure 8. The harmonic profile of the inverter in Figure 8 is shown in Figure 9.

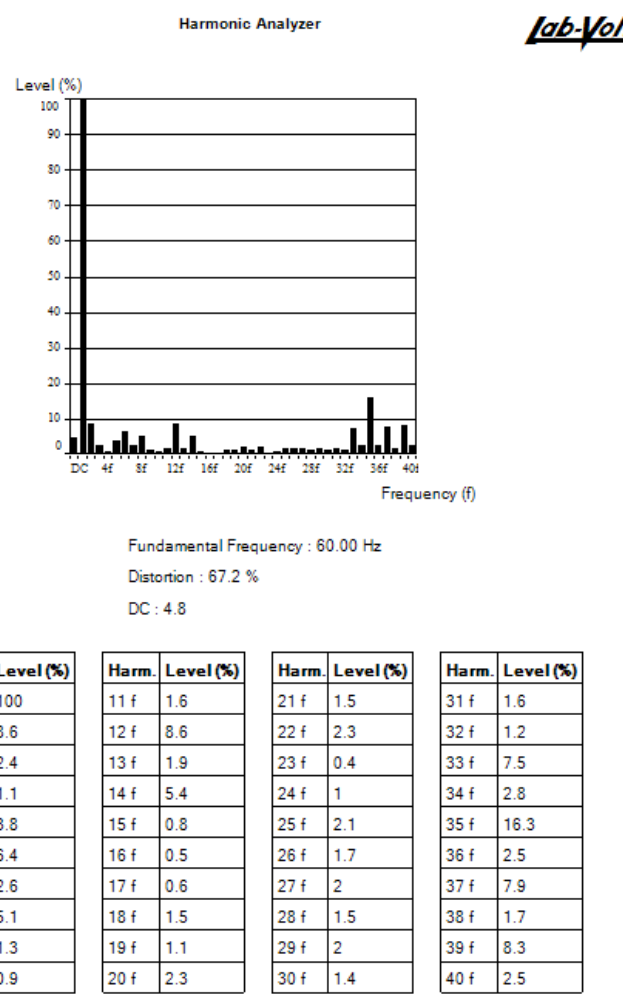

Figure 9. SPWM inverter voltage harmonic profile.

Students are asked a series of questions about how their inverters perform and how well the inverters' operation agrees with theory to conclude the lab.

C. Final Project - Full converter for a permanent-magnet wind turbine generator

Modern wind turbines with permanent-magnet generators use power electronics to control the power they inject to the grid ${ }^{9}$. This project tasks students with building a small version of these electronics in the lab. To begin the project, students are given the basic diagram of a full converter shown in Figure 10. 


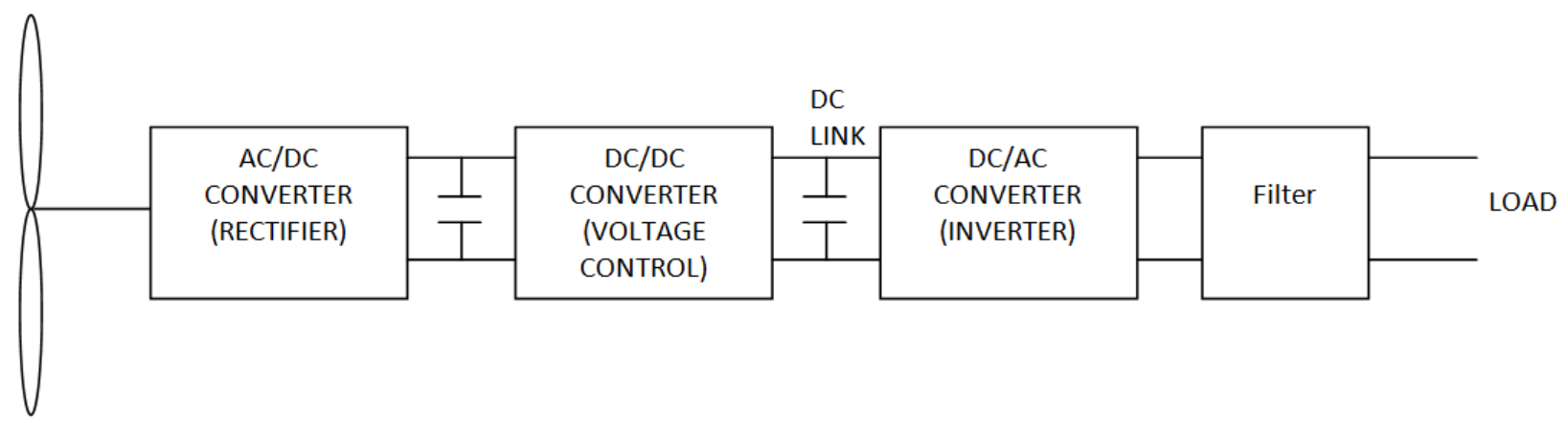

Figure 10. Full converter

For this project the wind generator is modeled by a synchronous machine with the field set and not allowed to change. Its range of operation is defined in terms of the voltage and frequency generated: $\mathrm{V}_{\mathrm{LN}}=6 \mathrm{~V}, \mathrm{f}=20 \mathrm{~Hz}$ to $\mathrm{V}_{\mathrm{LN}}=16.5 \mathrm{~V}, \mathrm{f}=40 \mathrm{~Hz}$. The load is a single-phase $200 \Omega$ power resistor. The design requirements are:

1. Load current THD $<30 \%$ over the entire operating range

2. Load current frequency must stay between $59 \mathrm{~Hz}$ and $61 \mathrm{~Hz}$ over the entire operating range.

3. Load voltage must stay between $6.5 \mathrm{~V}$ and $7.5 \mathrm{~V}$ over the entire operating range.

4. The Lab-Volt chopper/inverter may only be used to implement one circuit.

Obviously this is a very low-power application. The reason for the low voltages is that the large capacitors available in our electronics shop have a voltage rating of $35 \mathrm{~V}$. If we upgrade the capacitors in the future the voltage requirements will increase.

Students are free to use any circuit they see fit to complete the project. They will almost certainly use circuits from at least four previous labs: Rectifiers, DC/DC converters, Single phase inverters and filters, and PWM. Therefore this project will reinforce topics already covered, as well as give students a chance to see many circuits work together as one unit. This project is designed so that it takes groups of two or three students between 25 and 35 hours to complete. In order to complete the project each group must demonstrate its working circuit to the lab instructor and submit a formal report.

Figure 11 shows the schematic of the circuit built by the authors as a demonstration. The HCS08 in Figure 11 is an 8-bit microcontroller that is used to implement an open-loop controller for the boost chopper. Undergraduate electrical and computer engineering students at Kansas State University use the HCS08 in a course on microcontrollers, so most of the students taking the power electronics lab course will have some experience with it. All of the design requirements are met when the circuit in Figure 11 is operated in the range above. 


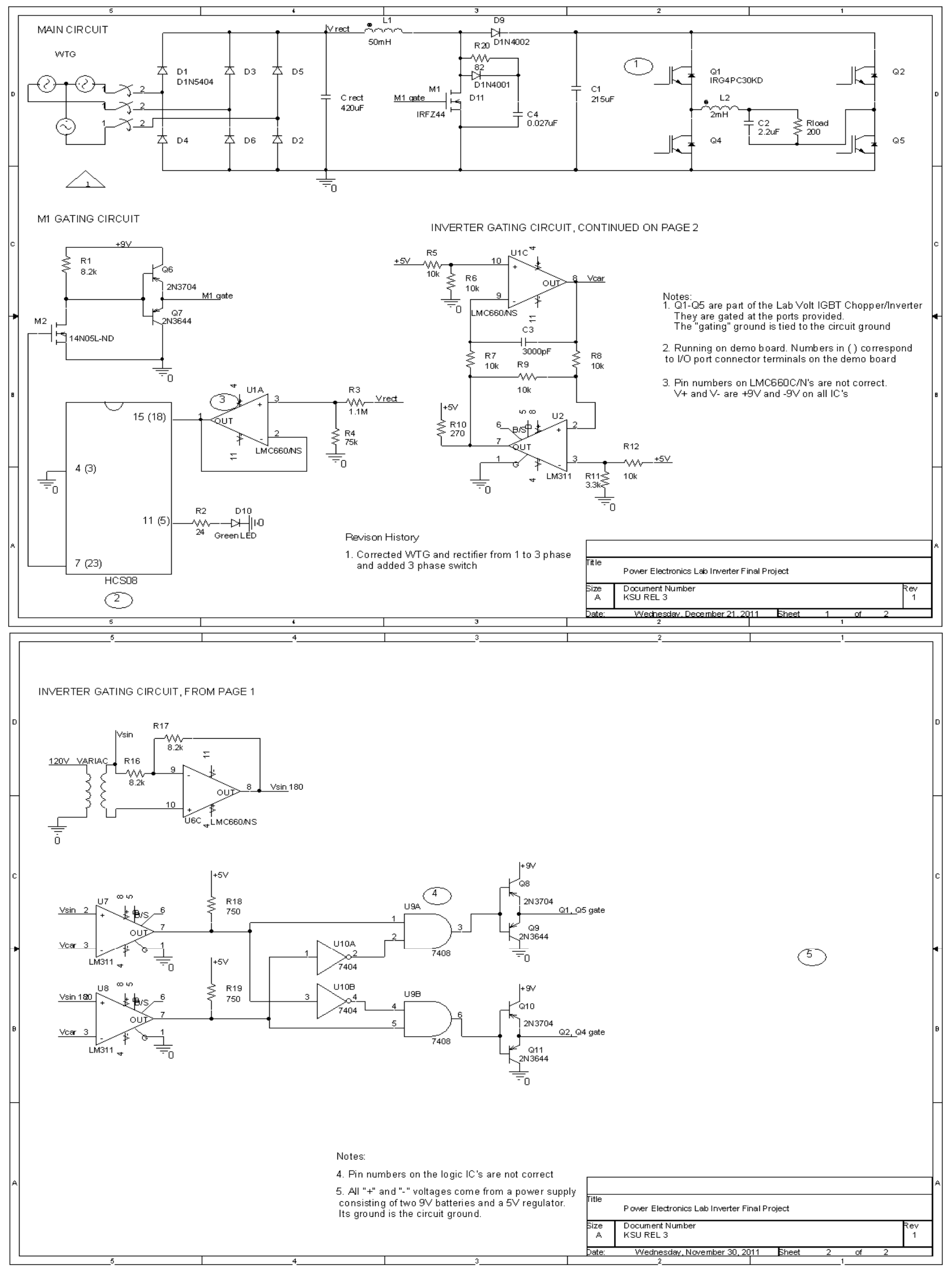

Figure 11. Full converter schematic 


\section{Results of End-of-Semester Evaluations}

The course was completed (except for Labs 2 and 11) in the Fall of 2011 by three undergraduate students and one graduate student as part of another class on wind and solar energy engineering. Two of the undergraduates and the graduate student are electrical engineering majors, and one undergraduate student is a biological and agricultural engineering student. As part of the anonymous end-of-semester evaluation of the wind and solar class, the students were posed questions specifically related to the labs. The results of those questions are presented in Table 1.

\begin{tabular}{|c|c|c|c|c|c|}
\hline Question & $\mathbf{1}$ & $\mathbf{2}$ & $\mathbf{3}$ & $\mathbf{4}$ & $\mathbf{5}$ \\
\hline $\begin{array}{c}\text { Please rate the difficulty } \\
\text { of the labs. }\end{array}$ & 0 & 0 & 1 & 2 & 1 \\
\hline & Too easy & Somewhat easy & Just right & Somewhat too difficult & Too difficult \\
\hline $\begin{array}{c}\text { Please rate the amount } \\
\text { you learned in the labs. }\end{array}$ & 0 & 0 & 3 & 2 & 1 \\
\hline $\begin{array}{c}\text { How reasonable was the } \\
\text { amount of time you spent } \\
\text { on the labs? }\end{array}$ & 0 & 0 & 2 & 2 & 0 \\
\hline & Too little & Somewhat too little & Just right & Somewhat too much & Too much \\
\hline
\end{tabular}

Table 1. End-of-semester evaluation results

The students were also asked to provide their opinions on open-ended questions. The first was "Do you feel that you learned skills in the lab that you haven't learned in lecture-style classes?" Three of the four students responded positively and the fourth did not respond. The second question was "What would you change about the labs if you were teaching it next semester?" Three of the four responses suggested making labs shorter and two of the four suggested providing more background information on the given topic before the lab starts.

Furthermore, as part of the students' grade for each lab, they were required to report how much time they spent on it. Another undergraduate student, a chemical engineering major, completed most of the labs during the Summer of 2011. That student's completion times were also recorded. The times the students reported are shown in Table 2.

\begin{tabular}{|l|l|l|l|l|l|l|l|l|l|l|l|}
\hline Lab & $\mathbf{1}$ & $\mathbf{2}$ & $\mathbf{3}$ & $\mathbf{4}$ & $\mathbf{5}$ & $\mathbf{6}$ & $\mathbf{7}$ & $\mathbf{8}$ & $\mathbf{9}$ & $\mathbf{1 0}$ & $\mathbf{1 1}$ \\
\hline Student 1 & 4.5 & N/A & 6.5 & 4 & NR & 4.33 & NR & 7.5 & 3.5 & N/A & N/A \\
\hline Student 2 & 5.5 & N/A & NR & 4 & NR & 4.5 & NR & 8.5 & 3.75 & N/A & N/A \\
\hline Student 3 & 2.75 & N/A & 8 & 3.58 & 6.5 & 4.5 & 4.5 & 8.25 & 4.5 & N/A & N/A \\
\hline Student 4 & NR & N/A & 7 & 4 & 7 & 5.5 & 4.5 & 8 & 4.5 & N/A & N/A \\
\hline Student 5 & 3 & N/A & 5.3 & 6 & N/A & 4.75 & 2.75 & 10.75 & 4 & N/A & N/A \\
\hline Mean time & 3.9375 & N/A & 6.7 & 4.316 & 6.75 & 4.716 & 3.9167 & 8.6 & 4.05 & N/A & N/A \\
\hline
\end{tabular}




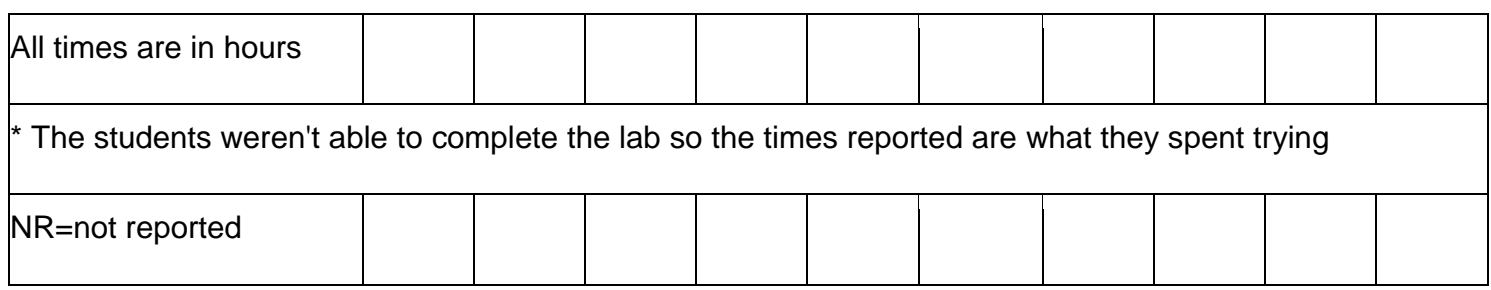

Table 2. Lab completion times

The times reported in Table 2 include the Pre-Lab section of each lab, which students are to complete before they arrive for class. Since the allotted time slot is 3 hours per week, Labs 3, 5, and 8 each require 2 weeks to complete, which is what was allotted to the students who completed the course. In the future, students will be given 3 weeks to complete the final project (Lab 10 or Lab 11). Labs 2 and 11 weren't ready for the students to try, and Labs 5 and 10 were attempted but no one was able to finish them. Once the issues that kept students from completing Labs 5 and 10 are corrected these labs will be the appropriate length for a 2 or 3 credit hour course at Kansas State University.

\section{Conclusions}

The outline and pedagogical theory of a laboratory course on power electronics, as well as 3 sample exercises, have been presented. Based on the results of the end-of-semester evaluations and the students' grades in the course, the authors conclude that the course meets its objectives as stated above. There is still room for improvement, however. Students were unable to successfully complete Lab 5 or Lab 10. They failed largely because of problems constructing their circuits on breadboards. In the future, greater emphasis will be placed on the importance of being neat and organized when using breadboards. Also, the students did not have the opportunity to complete Lab 2, in which they learn about gating techniques they can use in Lab 5. The results of the end-of-semester evaluations point to the need for giving students more background on the topic at hand before they attempt the lab. A single hour of lecture time every week in addition to the lab time would enable the instructor to provide that background and answer any questions students may have. Those measures will enable future students to successfully complete all of the labs. Funding has been approved to purchase more equipment for the lab, increasing the capacity to 8-12 students for the Fall 2012 semester.

\section{References}

1. R.S. Balog, Z. Sorchini, J.W. Kimball, P.L. Chapman, P.T. Krein, "Modern laboratory-based education for power electronics and electric machines," IEEE Transactions on Power Systems, vol. 20, no. 2, May 2005.

2. S. Choi, M. Saeedifard, R. Shenoy, “A Modern Education Power Electronics Laboratory to Enhance Hands-on Active Learning," in Proceedings of the 2011 ASEE Annual Conference \& Exposition, Vancouver, B.C, Canada, June 2011, session T123A. 
3. R.h. Chu,D.D.-C. Lu, S. Sathiakumar, "Project-Based Lab Teaching for Power Electronics and Drives," IEEE Transactions on Education, vol. 51, no. 1, February 2008.

4. J.M. Williams, J.L. Cale, N.D. Benavides, J.D. Wooldridge, A.C. Koening, J.L. Tichenor, S.D. Pekarek. "Versatile hardware and software tools for educating students in power electronics," IEEE Transactions on Education, vol. 47, no. 4, November 2004.

5. W.G. Hurley, L.C. Kwan, " Development, implementation, and assessment of a web-based power electronics laboratory," IEEE Transactions on Education, vol. 48, no. 4. November 2005.

6. D.A. Torrey, “A project-oriented power electronics laboratory," IEEE Transactions on Power Electronics, vol. 9, no. 3, May 1994.

7. B.K. Bose, Power Electronics and Motor Drives: Advances and Trends, Academic Press, Massachusetts, 2006.

8. M.H. Rashid, Power Electronics Circuits, Devices, and Applications, $2^{\text {nd }}$ ed., Prentice Hall, New Jersey, 1993.

9. D.D. Banham-Hall, G.A. Taylor, C.A. Smith, M.R. Irving, "Towards large-scale direct drive wind turbines with permanent magnet generators and full converters," in Proceedings of the 2010 IEEE Power and Energy Society General Meeting, Uxbridge, UK, July 2010. 